\title{
Ordered porous carbon with tailored pore size for electrochemical hydrogen storage application
}

\author{
Baizeng Fang, Haoshen Zhou, and Itaru Honma \\ Nano-Energy Materials Group, Energy Technology Institute, National Institute of Advanced Industrial \\ Science and Technology (AIST), Umezono 1-1-1, Tsukuba, Ibaraki 305-8568, Japan
}

\section{Supporting Information}

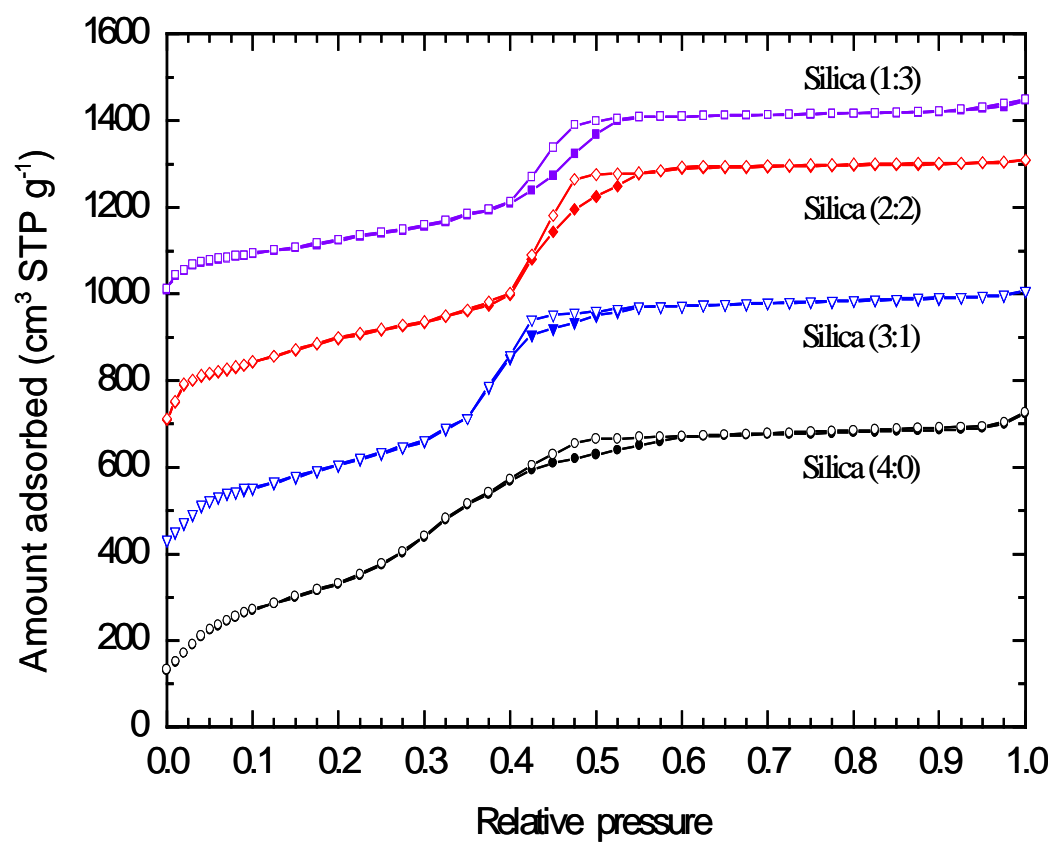

Figure S1. N2 adsorption-desorption isotherms at $77 \mathrm{~K}$ for the calcined silica samples obtained at various ratios of $\mathrm{HTAB}$ to $\mathrm{C}_{16} \mathrm{EO}_{8}$. The isotherms for Silica (3:1), Silica (2:2) and silica (1:3) were incremented by 300, 600 and $900 \mathrm{~cm} 3$ STP g-1, respectively. 


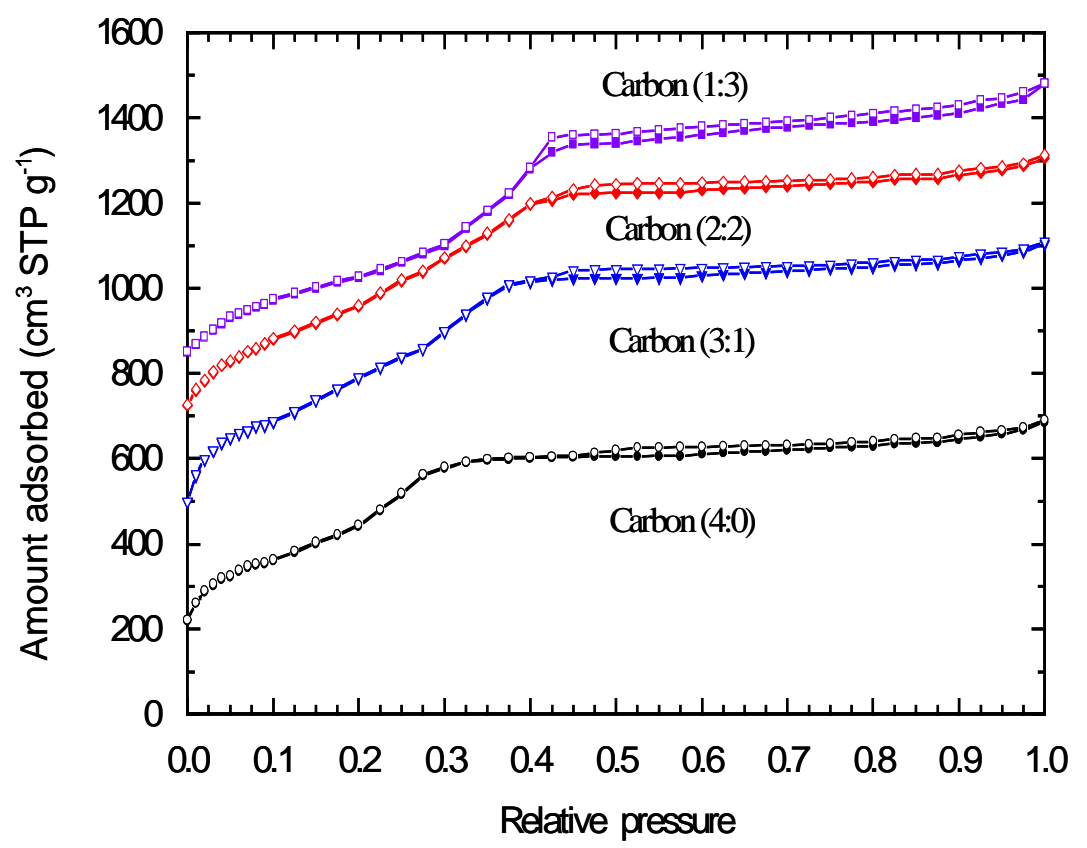

Figure S2. N2 adsorption-desorption isotherms at $77 \mathrm{~K}$ for the carbons obtained by using various silica templates which were obtained at various ratios of $\mathrm{HTAB}$ to $\mathrm{C}_{16} \mathrm{EO}_{8}$. The isotherms for carbon (3:1), carbon (2:2) and carbon (1:3) were incremented by 200, 400 and $600 \mathrm{~cm} 3$ STP g-1, respectively. 


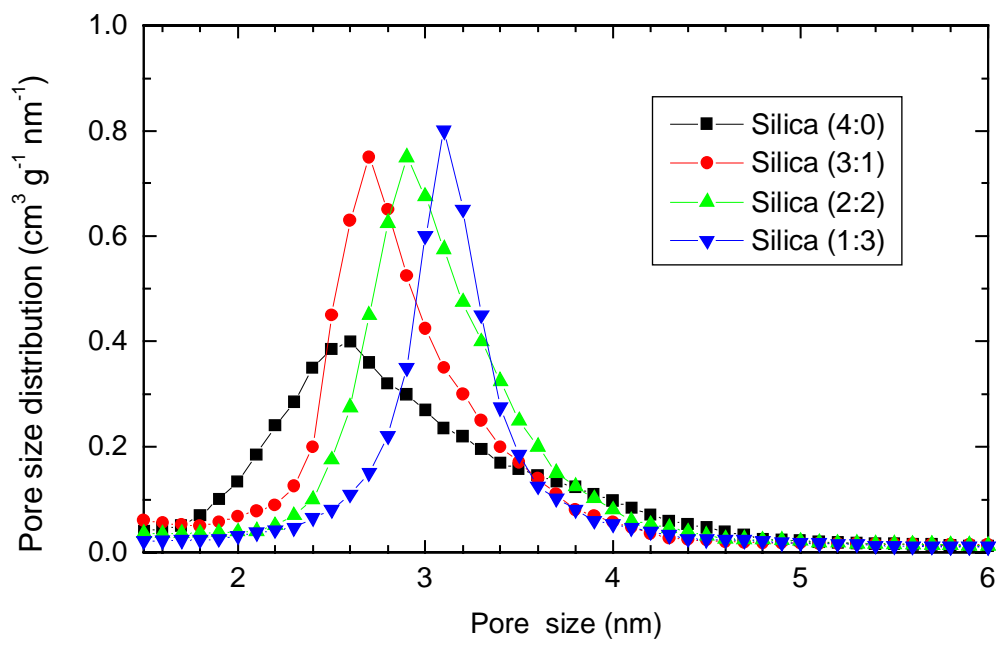

Figure S3. Pore size distribution for silica templates obtained at various ratios of HTAB to $\mathrm{C}_{16} \mathrm{EO}_{8}$ 


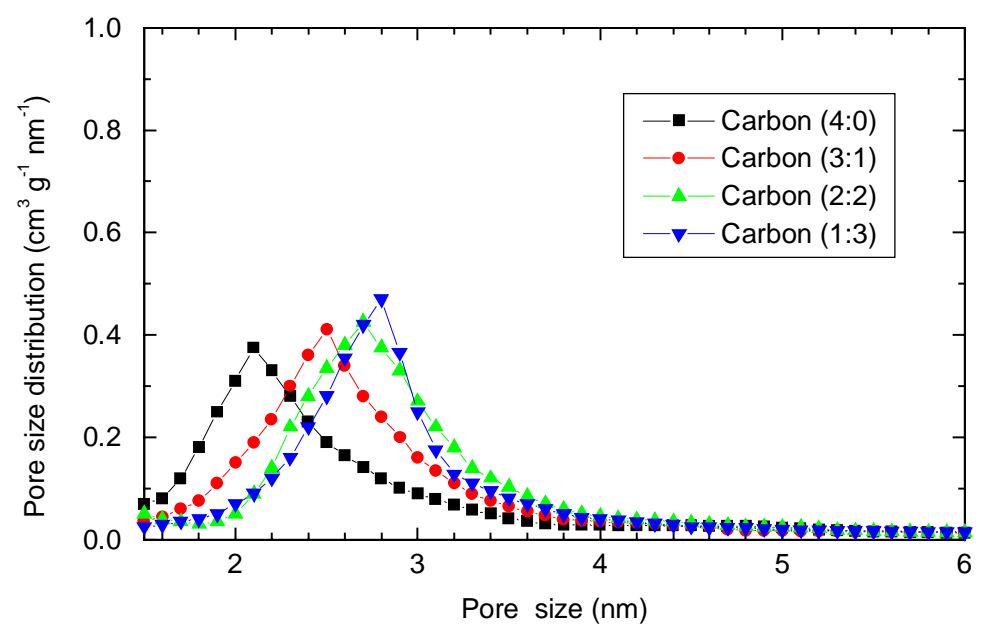

Figure S4. Pore size distribution for the carbon materials by using various silica templates which were obtained at various ratios of $\mathrm{HTAB}$ to $\mathrm{C}_{16} \mathrm{EO}_{8}$. 


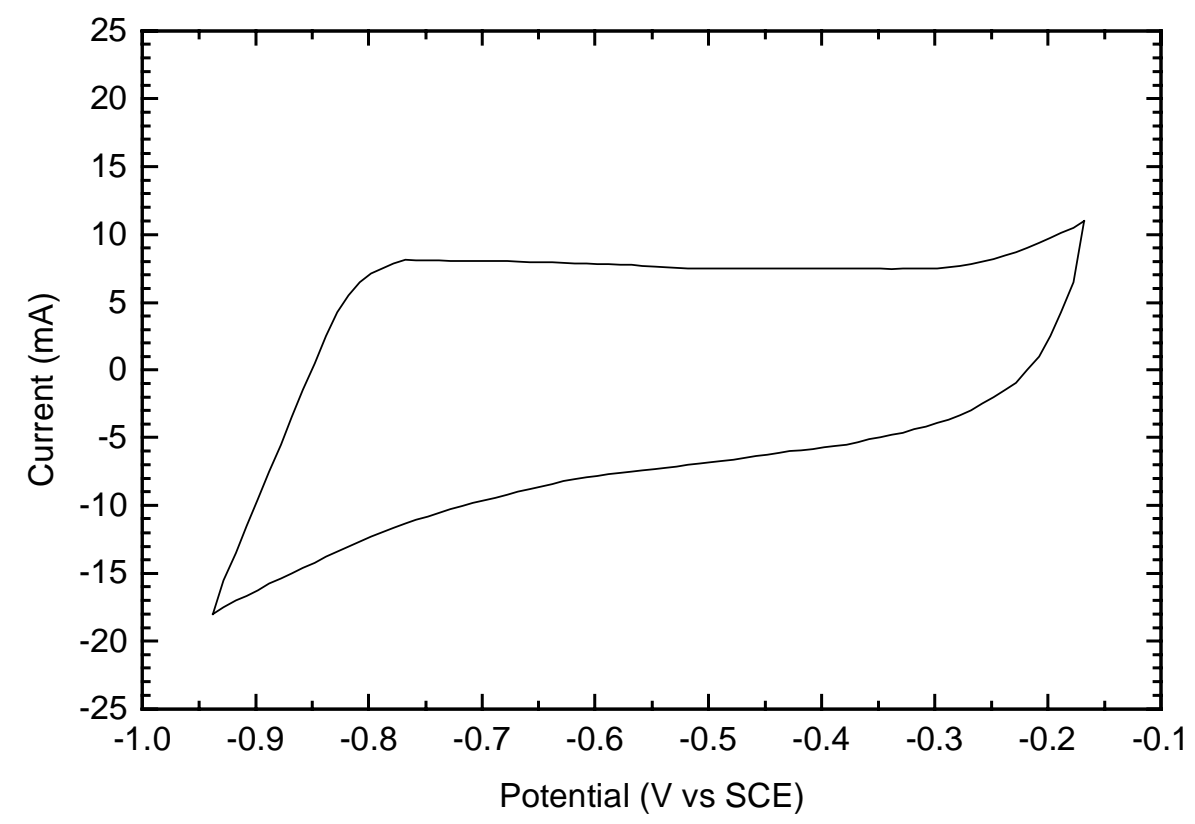

Figure S5. A typical cyclic voltammogram for the ordered carbon (4:0) in $6 \mathrm{M} \mathrm{KOH}$ at a scan rate of $5 \mathrm{mV} / \mathrm{s}$. Active material mass: $6.5 \mathrm{mg}$. 